\title{
Nutrientes minerais na biomassa da parte aérea em culturas de cobertura de solo(1)
}

\author{
Clóvis Manuel Borkert(2), Celso de Almeida Gaudêncio ${ }^{(3)}$, José Erivaldo Pereira ${ }^{(3)}$, Leonardo Régis Pereira(2)
} e Adilson de Oliveira Junior(4)

\begin{abstract}
Resumo - $\mathrm{O}$ objetivo deste trabalho foi estimar as quantidades de nutrientes reciclados por cinco espécies vegetais utilizadas como culturas de cobertura do solo e que podem retornar ao solo pela mineralização da biomassa. Foram coletadas de vários experimentos amostras da matéria verde de aveia-preta (Avena strigosa Schreb), mucuna-preta (Stizolobium aterrimum Piper \& Tracy), guandu (Cajanus cajan (L.) Millsp), tremoço (Lupinus albus L. e L. angustifolius L.) e ervilhaca (Vicia sativa L.). Foi estimado o rendimento de matéria seca e determinados os teores de $\mathrm{N}, \mathrm{P}, \mathrm{K}, \mathrm{Ca}, \mathrm{Mg}, \mathrm{Mn}, \mathrm{Zn}, \mathrm{Cu}$, e, a partir dessas concentrações, foram calculadas a média observada, a média estimada e o intervalo de confiança a $95 \%$ para cada nutriente dentro de cada classe de rendimento de matéria seca, em cada espécie vegetal. Os dados foram tabulados dentro de intervalos de classe de rendimento de matéria seca e apresentadas as quantidades estimadas de nutrientes minerais. Foram ajustadas equações para estimar as quantidades desses nutrientes. A aveia-preta e a ervilhaca reciclam grande quantidade de $\mathrm{K}$, e a ervilhaca, a mucuna-preta, o tremoço e o guandu reciclam grande quantidade de $\mathrm{N}$. Todas as espécies reciclam quantidades apreciáveis de $\mathrm{Ca}, \mathrm{Mg}$ e micronutrientes, porém baixas quantidades de $\mathrm{P}$. A rotação de culturas é um meio de implementar com sucesso o aumento das áreas de lavoura em semeadura direta.
\end{abstract}

Termos para indexação: plantas de proteção, reciclagem de nutriente, mineralização, rotação de culturas.

\section{Mineral nutrients in the shoot biomass of soil cover crops}

Abstract - The objective of this work was to estimate the quantity of nutrients recycled by five species of cover crops and returned to the soil after the mineralization of the biomass. Fresh samples of several experiments of black oats (Avena strigosa Schreb), black mucuna (Stizolobium aterrimum Piper \& Tracy), pigeon pea (Cajanus cajan (L.) Millsp), lupin (Lupinus albus L. and L. angustifolius L.) and common vetch (Vicia sativa $\mathrm{L}$.) were taken to estimate dry matter yield and determine the content of N, $\mathrm{P}, \mathrm{K}, \mathrm{Ca}, \mathrm{Mg}, \mathrm{Mn}, \mathrm{Zn}$, and $\mathrm{Cu}$. From the dry matter yield, nutrient content were analyzed, and the estimated and observed mean, and a confidence limit at the $95 \%$ level, for each nutrient, in each class of dry matter yield and in each cover crop species were calculated. The data were tabulated with the corresponding dry matter class intervals and estimated quantity of nutrients. Equations were adjusted to estimate the quantity of nutrients in relation to dry matter yield. Black oats and common vetch, are good for recycling $\mathrm{K}$, and common vetch, black mucuna, lupin and pigeon pea recycled large amounts of $\mathrm{N}$. All species recycled large amounts of $\mathrm{Ca}, \mathrm{Mg}$ and micronutrients, but small amounts of P. Crop rotation is a way of successfully increasing field areas under no-tillage.

Index terms: protective plants, nutrient recycling, mineralization, rotational cropping.

(1) Aceito para publicação em 16 de setembro de 2002.

(2) Embrapa-Centro Nacional de Pesquisa de Soja (CNPSo), Caixa Postal 231, CEP 86001-970 Londrina, PR. Bolsista do CNPq. E-mail: borkert@cnpso.embrapa.br, leonardo@cnpso.embrapa.br

(3)Embrapa-CNPSo. E-mail: celalg@sercomtel.com.br, erivaldo@cnpso.embrapa.br

(4) Universidade Federal de Viçosa, Av. P.H. Rolfs, s/no CEP 36571-000 Viçosa, MG. Bolsista da Capes. E-mail: adilson@solos.ufv.br

\section{Introdução}

A área de cultivo de soja em semeadura direta no Paraná tem crescido nos últimos anos. Na safra 2001/ 2002, a área total foi de 3.296.575 ha (Paraná, 2002), sendo 2.703.192 ha (82\%) em semeadura direta (SD). No inverno de 2002, a área total cultivada com trigo foi de 1.020.624 ha (Paraná, 2002), sendo 734.850 ha (72\%) em SD. Embora a área em SD venha aumentan- 
do a cada ano, as áreas onde se pratica a rotação de culturas ainda são muito reduzidas, exceto as semeadas com aveia-preta e com aveia-branca no inverno, cujo total é de 177.800 ha (Paraná, 2002), incluindo-se as áreas de semeadura direta e convencional. O cultivo de milho na safra normal e na safrinha ocupa área de aproximadamente 2.502.339 ha (Paraná, 2002), porém, a prática de rotação de culturas com outras espécies na sucessão soja-trigo ainda é pouco usada pelos agricultores. Outras opções de rotação no verão, como mucuna, crotalária, guandu e lab-lab; e no inverno, tremoço, ervilha forrageira, ervilhaca, nabo forrageiro e girassol, não são ainda bem difundidas.

A prática de rotação de culturas, substituindo a sucessão soja-trigo, pode ser importante no controle de pragas, doenças e ervas daninhas, assim também como forma de manejo da fertilidade do solo, pela capacidade de reciclar os nutrientes minerais da camada arável e os que tenham percolado para horizontes abaixo dela.

Os nutrientes essenciais para o crescimento das plantas e animais se movimentam através dos solos, das plantas, dos animais e dos resíduos de origem vegetal e animal. Essa sequiência de transferências, através de uma série de compartimentos, representa a forma mais simples de reciclagem de nutrientes. Na prática, embora existam diversos sistemas naturais controlados pelo homem, há muito mais compartimentos e transferências envolvidos na reciclagem que as indicadas num sistema simplificado (Spain \& Salinas, 1985). Na reciclagem de nutrientes, muitos ciclos são policíclicos, o que significa que um elemento pode se reciclar mediante vários processos, dentro de um compartimento (solo) antes de ser transferido ao próximo compartimento (planta). O tempo para que um nutriente complete um ciclo varia de minutos, em transferências que envolvem microrganismos, a meses, para absorção e crescimento das plantas em cultivos anuais, a anos, para o consumo e crescimento de animais, e até a milhares e milhões de anos, para as transferências que envolvem ambiente físico, atmosfera, terra, mar e formação de rochas (Newbould, 1978).

A maioria dos trabalhos (Igue et al., 1984; Derpsch et al., 1991) que envolvem plantas de cobertura de solo em rotações de culturas, somente tem avaliado o rendimento de matéria verde e seca dessas espécies e, em alguns deles (De-Polli \& Chada, 1989; Derpsch et al., 1991; Sá, 1993; Wisniewski \& Holtz, 1997), somente foram determinadas as quantidades de $\mathrm{N}$ e $\mathrm{P}$ presentes na biomassa e passíveis de serem reciclados; outros trabalhos apresentam a composição química de algumas espécies (Calegari, 1990, 1995; Derpsch \& Calegari, 1992). Pouca pesquisa foi realizada para estimar as quantidades de nutrientes que são recicladas pelas espécies utilizadas na cobertura de solo nos sistemas de rotação de culturas na sucessão soja-trigo.

Na recomendação da adubação da soja em semeadura direta, utilizam-se os mesmos parâmetros de recomendação aplicados ao sistema de cultivo convencional, embora alguns cuidados e ajustes devam ser feitos (Anghinoni \& Salet, 1996). Porém, as recomendações de adubação são feitas sem considerar os nutrientes que são reciclados pelas espécies que antecedem a soja, e que no sistema de semeadura direta permanecem sobre o solo como "mulch" para protegê-lo dos efeitos climáticos e da erosão. Essa biomassa, ao ser mineralizada, libera nutrientes que podem ser aproveitados pela cultura subseqüente.

A mineralização dos restos de culturas de cobertura, considerando somente os compartimentos planta e solo, é um sistema aberto com entrada de nutrientes via adubos e restos vegetais, que mineralizam em diferentes velocidades, sem considerar outras entradas, como a água da chuva; as saídas ocorrem pelas perdas por volatilização, lixiviação, percolação e escorrimento por erosão laminar. No caso do N, que é um elemento muito móvel no sistema, e, mesmo com as perdas citadas, estima-se que $60 \%$ a $70 \%$ desse nutriente encontrado na biomassa vegetal heterotrófica é reciclado e novamente absorvido pelas plantas do cultivo seguinte (Spain \& Salinas, 1985). A quantidade de $\mathrm{N}$ que retorna ao solo na forma de resíduos de plantas constitui considerável porção do $\mathrm{N}$ total absorvido pelas plantas (Whitney \& Kanehiro, 1967), comparada à pequena parte do que é liberado pelas raízes e do que é lavado das folhas pela chuva.

Segundo Jones \& Woodmansee (1979), cerca de $77 \%$ do $\mathrm{P}$ das folhas e $79 \%$ do $\mathrm{P}$ das raízes mortas ficam disponíveis para o crescimento das plantas cultivadas logo após o cultivo da cultura de cober- 
tura. Desse total de P na parte aérea da planta, $60 \%$ a $80 \%$ são solúveis em água, a maior parte na forma orgânica (Bromfield \& Jones, 1970). Embora o P seja pouco solúvel, pode retornar ao solo por chuvas de alta intensidade (Bromfield, 1961). Entre 69\% e 80\% do P total na planta pode ser lavado da vegetação dessecada ou morta (Wilkinson \& Lowrey, 1973). A intensidade e duração da chuva e o intervalo entre dormência ou senescência do tecido e a primeira precipitação afetam as quantidades de $\mathrm{P}$ que retornam ao solo proveniente dessa biomassa em estado latente ou morta.

O K é normalmente o mineral mais abundante no tecido vegetal, e como ele se apresenta predominantemente na forma iônica $\mathrm{K}^{+}$, a decomposição dos restos vegetais o libera na sua totalidade rapidamente. Assim, pode-se considerar como $100 \%$ o aproveitamento do K proveniente dos restos de culturas, porém podem ocorrer perdas por lixiviação, quando se trata de solos arenosos (Spain \& Salinas, 1985). Quanto ao Ca, Mg e micronutrientes, existem na literatura poucos registros de concentração desses nutrientes na matéria seca (Calegari, 1990, 1995; Derpsch \& Calegari, 1992).

O objetivo deste trabalho foi estimar as quantidades de nutrientes reciclados por cinco espécies vegetais utilizadas como culturas de cobertura do solo e que podem retornar ao solo pela mineralização da biomassa.

\section{Material e Métodos}

As amostras para estimar os teores de nutrientes da biomassa vegetal foram coletadas nos experimentos de rotação de cultura e de cultivares de aveia-preta nos municípios paranaenses de Campo Mourão, Guarapuava e Londrina. Os experimentos foram iniciados em 1985 (Campo Mourão), em 1987 (Guarapuava), e em 1984 (Londrina), por ocasião do início dos ciclos de rotação de culturas, tanto no inverno como no verão, para serem comparados com a sucessão soja-trigo, realizada todos os anos. A partir de 1986, foram coletadas amostras de plantas das espécies utilizadas nas diversas combinações de rotação de culturas e amostras dos experimentos com aveia, durante seis anos, para calcular o rendimento de matéria seca (MS) e obter os teores de nutrientes, de modo a estimar a quantidade de macro e micronutrientes que retornam ao solo na biomassa e que poderá ser mineralizada.
A espécie com maior número de amostras (333) foi a aveia-preta (Avena strigosa Schreb), por sua participação nas combinações de sistemas de rotação e nos experimentos de cultivares. Durante quatro anos, foram coletadas 87 amostras de tremoço (Lupinus albus L. e L. angustifolius L.), 59 de guandu (Cajanus cajan (L.) Millsp), 29 de mucuna-preta (Mucuna aterrima, sinônimo Stizolobium aterrimum) e 12 de ervilhaca comum (Vicia sativa L.).

Todas as amostras foram coletadas de forma aleatória numa área de $0,5 \mathrm{~m}^{2}$ por parcela nas culturas de outono/ inverno, e de $1 \mathrm{~m}^{2}$ nas de verão, na época do início do enchimento de grãos das espécies, para estimar o rendimento de MS, da qual foram retiradas amostras para determinação dos teores totais de $\mathrm{N}, \mathrm{P}, \mathrm{K}, \mathrm{Ca}, \mathrm{Mg}, \mathrm{Zn}, \mathrm{Cu}$ e $\mathrm{Mn}$. Na determinação do $\mathrm{N}$ total no tecido vegetal, a digestão das amostras foi realizada via úmida (Bremner, 1965), e do N pelo método de indofenol (Miyazawa et al., 1992).

$\mathrm{Na}$ análise de outros nutrientes, usou-se a digestão nitroperclórica (Vitti et al., 2000), sendo o P determinado pelo método colorimétrico com azul de molibdênio, o K por fotometria de chama, e o $\mathrm{Ca}, \mathrm{o} \mathrm{Mg}$, o Zn, o $\mathrm{Mn}$ e o $\mathrm{Cu}$, por espectrofotometria de absorção atômica (Miyazawa et al., 1992).

O teor total de cada nutriente foi estimado a partir da porcentagem do nutriente presente em cada amostra, multiplicada pelo peso total de matéria seca estimada em toneladas por hectare. Assim, foram estimados os teores dos nutrientes presentes em $\mathrm{kg} / \mathrm{ha}$, para cada uma das cinco espécies, em razão da quantidade de matéria seca produzida.

Como o rendimento total de MS pode variar muito de acordo com o ano, local e nível de fertilidade do solo, foram coletadas amostras por seis anos, em três locais. O solo apresentava fertilidade adequada, pois havia recebido calcário, no início dos experimentos, e adubações anuais de $\mathrm{P}$ e K, nas culturas da soja e trigo, mais a aplicação de $\mathrm{N}$ no trigo. Assim, foram estabelecidos intervalos de classe em relação ao rendimento de MS. Nas espécies que apresentaram grande amplitude de rendimento de MS e grande número de observações, como a aveia-preta e o guandu, foram criadas seis classes. Em relação ao tremoço e à mucuna, com menor número de observações, foram criadas quatro classes; no caso da ervilhaca, com 12 observações, optou-se em não criar classes, apresentando as médias e o maior e o menor valor observados, cuja diferença foi pequena. Neste caso, ajustaram-se equações para estimar as quantidades de nutrientes minerais reciclados, em razão da quantidade de MS produzida.

Nas quatro espécies com maior número de observações, foram determinados, quanto aos pares de rendimento de MS, a quantidade total do nutriente mineral, a média observada, a média estimada e o intervalo de confiança a 
95\%, para cada um dos nutrientes, dentro de cada classe de rendimento de MS de cada espécie.

Para cada espécie foram ajustadas equações de regressão, relacionando a quantidade média de nutriente reciclado em razão da quantidade média de MS produzida em cada classe. A equação ajustada foi utilizada para estimar o valor médio e o respectivo intervalo de confiança da quantidade de nutriente em cada classe.

\section{Resultados e Discussão}

O rendimento de MS da aveia-preta estimado a partir de 333 amostras ficou distribuído dentro de seis intervalos de classe com produções variando desde menos de $5 \mathrm{t} \mathrm{ha}^{-1}$ até mais de $15 \mathrm{t} \mathrm{ha}^{-1}$. Porém, na maioria das parcelas amostradas, o rendimento de MS ficou nos intervalos $>5$ a 7,5 $\mathrm{t} \mathrm{ha}^{-1}, 27,6 \%(\mathrm{n}=92)$ e >7,5 a $10 \mathrm{t} \mathrm{ha}^{-1}, 30,3 \%(\mathrm{n}=101)$ (Tabela 1$)$. O rendimento de MS obtido está próximo dos valores encontrados por Calegari (1990), para aveia-preta, no sul do Paraná, numa amplitude de 4,7 a 7,3 t ha-1, e dos dados apresentados por Bulisani et al. (1992).

A quantidade de $\mathrm{N}$ total contida na biomassa da aveia-preta indica que, embora não seja uma leguminosa, acumula e recicla quantidade razoável de $\mathrm{N}$, segundo nutriente de maior quantidade na biomassa após o K (Tabela 2). Esses valores estão próximos dos apresentados por Calegari, (1990), Derpsch et al. (1991) e Derpsch \& Calegari, (1992).

$\mathrm{O} \mathrm{P}$, entre os macronutrientes, é o reciclado em menor quantidade pela aveia-preta, variando de 8 a $12 \mathrm{~kg} \mathrm{ha}^{-1}$, no intervalo de classe $>5$ a $10 \mathrm{t} \mathrm{ha}^{-1} \mathrm{de}$ MS (Tabela 2). O teor de K total da aveia-preta é maior em relação às outras espécies estudadas, exceto ao tremoço, que também extrai elevada quantidade de $\mathrm{K}$ do solo. A aveia-preta pode servir como recicladora desse nutriente, por possuir sistema radicular profundo, permitindo trazer para a camada superficial do solo o K lixiviado para horizontes abaixo da camada arável (0-20 cm).

A aveia-preta também recicla $\mathrm{Ca}$ e $\mathrm{Mg}$, podendo retornar ao solo, em média, $68 \mathrm{~kg} \mathrm{ha}^{-1}$ de $\mathrm{Ca}$ e $20 \mathrm{~kg} \mathrm{ha}^{-1} \mathrm{de} \mathrm{Mg}$, com rendimento de 7,5 a $10 \mathrm{tha}^{-1}$ de MS (Tabela 2). Quanto aos micronutrientes, a aveia-preta é eficiente recicladora de $\mathrm{Mn}$, com quantidades acumuladas de $2.484 \mathrm{~g} \mathrm{ha}^{-1}$ de $\mathrm{Mn}, 182 \mathrm{~g} \mathrm{ha}^{-1}$ de $\mathrm{Zn}$ e $77 \mathrm{~g} \mathrm{ha}^{-1}$ de $\mathrm{Cu}$, no intervalo de rendimento de 7,5 a $10 \mathrm{t} \mathrm{ha}^{-1}$ de MS. Todos os valores observa- dos e estimados das quantidades de nutrientes minerais que retornam ao solo pela mineralização da biomassa da aveia-preta, comprovam sua eficiência como planta de cobertura do solo e sua capacidade de reciclar nutrientes.

As quantidades intermediárias de nutrientes minerais que retornam ao solo, em razão do rendimento de MS de aveia-preta, foram estimadas por meio de equações de regressão linear (Tabela 3 ). Os coeficientes de determinação dos modelos ajustados em relação ao $\mathrm{P}$ e ao $\mathrm{Mg}$, embora tenham sido mais baixos que os dos outros nutrientes, foram significativos a $5 \%$.

O rendimento de MS do guandu foi estimado a partir de 59 amostras e distribuído dentro de seis intervalos de classe, variando desde $<2 \mathrm{t} \mathrm{ha}^{-1}$ até $>10$ t ha $^{-1}$ de MS, com distribuição de freqüência homogênea, entre 8 e 14 amostras, em cada intervalo de classe, exceto nos rendimentos maiores que

Tabela 1. Intervalo de classe em relação ao rendimento de matéria seca (MS), freqüência do número de amostras coletadas e rendimento médio de matéria seca de quatro espécies vegetais usadas como cobertura do solo.

\begin{tabular}{|c|c|c|}
\hline $\begin{array}{l}\text { Intervalo de classe } \\
\left(\mathrm{t} \mathrm{ha}^{-1}\right)\end{array}$ & $\begin{array}{l}\text { Freqüuência } \\
\text { (n) }\end{array}$ & $\begin{array}{l}\text { Rendimento médio } \\
\text { de MS }\left(\mathrm{t} \mathrm{ha}^{-1}\right)\end{array}$ \\
\hline \multicolumn{3}{|c|}{ Aveia-preta } \\
\hline$<5,0$ & 41 & 4,07 \\
\hline$>5,0$ a 7,5 & 92 & 6,35 \\
\hline$>7,5$ a 10,0 & 101 & 8,75 \\
\hline$>10,0$ a 12,5 & 55 & 11,13 \\
\hline$>12,5$ a 15,0 & 26 & 13,46 \\
\hline$>15$ & 18 & 18,26 \\
\hline \multicolumn{3}{|c|}{ Guandu } \\
\hline$<2,0$ & 11 & 1,39 \\
\hline$>2,0$ a 4,0 & 13 & 2,84 \\
\hline$>4,0$ a 6,0 & 8 & 4,72 \\
\hline$>6,0$ a 8,0 & 14 & 6,77 \\
\hline$>8,0$ a 10,0 & 10 & 9,05 \\
\hline$>10,0$ & 3 & 12,19 \\
\hline \multicolumn{3}{|c|}{ Mucuna-preta } \\
\hline$<2,5$ & 4 & 1,70 \\
\hline$>2,5$ a 5,0 & 9 & 3,94 \\
\hline$>5,0$ a 7,5 & 9 & 6,11 \\
\hline$>7,5$ & 7 & 8,64 \\
\hline \multicolumn{3}{|c|}{ Tremoço } \\
\hline$<7,0$ & 22 & 5,77 \\
\hline$>7,0$ a 10,0 & 19 & 8,63 \\
\hline$>10,0$ a 13,0 & 26 & 11,60 \\
\hline$>13,0$ & 20 & 14,37 \\
\hline
\end{tabular}


$10 \mathrm{t} \mathrm{ha}^{-1}$, constatou-se somente três observações (Tabela 1). O guandu é uma das opções para cobertura de solo no verão/outono, e pode produzir em consórcio com o milho quantidades de MS superiores a $2 \mathrm{t} \mathrm{ha}^{-1}$. Em alguns casos, produz mais de $10 \mathrm{t} \mathrm{ha}^{-1}$ quando cultivado isoladamente em solos férteis e com boas condições climáticas, conforme dados de Calegari (1995), que encontrou variação de 3 a 22 t ha ${ }^{-1}$ de MS. Monegat (1981) também constatou rendimento de MS de guandu de $10 \mathrm{t} \mathrm{ha}^{-1}$, em Chapecó, SC.

O conteúdo de $\mathrm{N}$ na MS de guandu variou de 43 a $288 \mathrm{~kg} \mathrm{ha}^{-1}$, o que significa elevadas quantidades acumuladas de $\mathrm{N}$ na biomassa e que grande parte desse $\mathrm{N}$ pode ser disponibilizado para a cultura da safra seguinte, pois, de acordo com Spain \& Salinas (1985), cerca de $70 \%$ (30 a $187 \mathrm{~kg} \mathrm{ha}^{-1}$ de N) poderá ser disponibilizado para a cultura seguinte.

A quantidade de $\mathrm{P}$ contida na aveia-preta, por unidade de biomassa, foi menor do que no guandu (Tabelas 2 e 4), visto que a quantidade observada e estimada de $\mathrm{P}$ na MS deste foi $33 \mathrm{~kg} \mathrm{ha}^{-1}$, quando o rendimento de MS foi maior que $10 \mathrm{tha}^{-1}$ (Tabela 4). Calegari (1995) observou 0,14\% de P na MS de guandu, ou seja, em $10 \mathrm{t} \mathrm{ha}^{-1}$ de MS produzida, acumulam-se $14 \mathrm{~kg} \mathrm{ha}^{-1}$ de $\mathrm{P}$, valor que corresponde a aproximadamente $50 \%$ do conteúdo de $\mathrm{P}$ na MS, conforme observado no presente trabalho.

Tabela 2. Quantidades de nutrientes minerais contidos na matéria seca (MS) da aveia-preta passíveis de retornar ao solo pela mineralização da biomassa.

\begin{tabular}{|c|c|c|c|c|c|c|}
\hline \multirow[t]{2}{*}{ Variável } & \multicolumn{6}{|c|}{ Intervalo de classe de rendimento de $\mathrm{MS}\left(\mathrm{t} \mathrm{ha}^{-1}\right)$} \\
\hline & $<5$ & $>5,0$ a 7,5 & $>7,5$ a 10 & $>10$ a 12,5 & $>12,5$ a 15 & $>15$ \\
\hline & \multicolumn{6}{|c|}{ Nitrogênio $\left(\mathrm{kg} \mathrm{ha}^{-1}\right)$} \\
\hline Média observada & 59 & 80 & 123 & 169 & 188 & 224 \\
\hline Média estimada & 63 & 92 & 121 & 150 & 179 & 238 \\
\hline \multirow[t]{2}{*}{ IC a $95 \%$} & 37 a 90 & 71 a 112 & 104 a 138 & 134 a 166 & 160 a 198 & 207 a 269 \\
\hline & \multicolumn{6}{|c|}{ Fósforo $\left(\mathrm{kg} \mathrm{ha}^{-1}\right)$} \\
\hline Média observada & 4 & 8 & 12 & 18 & 24 & 18 \\
\hline Média estimada & 7 & 10 & 12 & 15 & 18 & 24 \\
\hline \multirow[t]{2}{*}{ IC a $95 \%$} & 0 a 16 & 2 a 17 & 7 a 18 & 10 a 21 & 11 a 24 & 13 a 34 \\
\hline & \multicolumn{6}{|c|}{ Potássio $\left(\mathrm{kg} \mathrm{ha}^{-1}\right)$} \\
\hline Média observada & 100 & 148 & 199 & 235 & 273 & 507 \\
\hline Média estimada & 75 & 136 & 201 & 265 & 328 & 457 \\
\hline \multirow[t]{2}{*}{ IC a $95 \%$} & 0 a 155 & 73 a 199 & 150 a 252 & 216 a 314 & 270 a 386 & 362 a 551 \\
\hline & \multicolumn{6}{|c|}{ Cálcio $\left(\mathrm{kg} \mathrm{ha}^{-1}\right)$} \\
\hline Média observada & 28 & 41 & 67 & 95 & 99 & 180 \\
\hline Média estimada & 20 & 43 & 68 & 93 & 118 & 168 \\
\hline \multirow[t]{2}{*}{ IC a $95 \%$} & 0 a 42 & 25 a 61 & 59 a 83 & 79 a 107 & 101 a 134 & 140 a 194 \\
\hline & \multicolumn{6}{|c|}{ Magnésio $\left(\mathrm{kg} \mathrm{ha}^{-1}\right)$} \\
\hline Média observada & 13 & 16 & 19 & 21 & 22 & 46 \\
\hline Média estimada & 10 & 15 & 20 & 24 & 29 & 39 \\
\hline \multirow[t]{2}{*}{ IC a $95 \%$} & 0 a 20 & 6 a 23 & 13 a 26 & 18 a 31 & 22 a 37 & 27 a 31 \\
\hline & \multicolumn{6}{|c|}{ Zinco $\left(\mathrm{g} \mathrm{ha}^{-1}\right)$} \\
\hline Média observada & 99 & 146 & 204 & 223 & 254 & 298 \\
\hline Média estimada & 117 & 149 & 182 & 215 & 248 & 314 \\
\hline \multirow[t]{2}{*}{ IC a $95 \%$} & 85 a 150 & 124 a 174 & 162 a 202 & 196 a 235 & 224 a 271 & 276 a 352 \\
\hline & \multicolumn{6}{|c|}{ Manganês $\left(\mathrm{g} \mathrm{ha}^{-1}\right)$} \\
\hline Média observada & 1.326 & 1.567 & 2.594 & 3.270 & 3.627 & 5.132 \\
\hline Média estimada & 1.198 & 1.826 & 2.484 & 3.138 & 3.779 & 5.091 \\
\hline \multirow[t]{2}{*}{ IC a $95 \%$} & 845 a 1.550 & 1.549 a 2.103 & 2.261 a 2.706 & 2.924 a 3.351 & 3.526 a 4.033 & 4.677 a 5.506 \\
\hline & \multicolumn{6}{|c|}{ Cobre $\left(\mathrm{g} \mathrm{ha}^{-1}\right)$} \\
\hline Média observada & 44 & 59 & 85 & 85 & 114 & 144 \\
\hline Média estimada & 44 & 60 & 77 & 94 & 111 & 145 \\
\hline IC a $95 \%$ & 27 a 62 & 48 a 73 & 67 a 88 & 82 a 107 & 93 a 129 & 114 a 176 \\
\hline
\end{tabular}


A quantidade de $\mathrm{K}$ encontrada na MS de guandu foi menor do que a da aveia-preta por unidade de massa. A quantidade máxima observada e estimada de $\mathrm{K}$ na MS de guandu foi de $174 \mathrm{~kg} \mathrm{ha}^{-1}$, em rendimento maior que $10 \mathrm{t} \mathrm{ha}^{-1}$ de MS (Tabela 4). Calegari (1995) encontrou valores de $261 \mathrm{~kg} \mathrm{ha}^{-1}$ de $\mathrm{K}$ com o guandu.

As quantidades de $\mathrm{Ca}$ e $\mathrm{Mg}$ passíveis de serem recicladas pela biomassa do guandu são menores do que as verificadas pela da aveia-preta (Tabelas $2 \mathrm{e} 4$ ). $\mathrm{O} \mathrm{Zn}$, o Mn e o Cu também são encontrados em menor quantidade na biomassa do guandu. Já o Mn é o micronutriente acumulado em maior quantidade na aveia-preta (Tabela 4).

As equações ajustadas para estimar as quantidades de nutrientes minerais possíveis de serem reciclados pela biomassa do guandu apresentaram coeficientes de determinação $\left(\mathrm{R}^{2}\right)$ acima de 0,83 e altamente significativos ( $\mathrm{p}<1 \%$ ), exceto a equação para estimar a quantidade de $\mathrm{Mn}$, cujo $\mathrm{R}^{2}$ foi significativo a $5 \%$ de probabilidade (Tabela 3 ).

O rendimento de MS de mucuna-preta foi estimado a partir de 29 amostras e distribuído dentro de quatro

Tabela 3. Equações ajustadas para estimar ( $\hat{Y}$ ) as quantidades de N, P, K, Ca e Mg, em kg ha-1, e de Zn, Mn e Cu, em $\mathrm{g} \mathrm{ha}^{-1}$, acumuladas na matéria seca (MS) de quatro espécies vegetais e que são passíveis de ser recicladas.

\begin{tabular}{|c|c|c|}
\hline Equação & $\mathrm{R}^{2}$ & $\mathrm{R}_{\text {ajustado }}^{2}$ \\
\hline \multicolumn{3}{|c|}{ Aveia-preta } \\
\hline$\hat{\mathrm{Y}}_{\mathrm{N}}=13,376042+0,012298 * *(\mathrm{MS})$ & $0,9640 * *$ & $0,9530 * *$ \\
\hline$\hat{\mathrm{Y}}_{\mathrm{P}}=2,051964+0,001179 *(\mathrm{MS})$ & $0,6627^{*}$ & $0,5784 *$ \\
\hline$\hat{\mathrm{Y}}_{\mathrm{K}}=-35,160527+0,026970 * *(\mathrm{MS})$ & $0,9294 * *$ & $0,9118 * *$ \\
\hline$\hat{\mathrm{Y}}_{\mathrm{Ca}}=-22,959517+0,010442 * *(\mathrm{MS})$ & $0,9606 * *$ & $0,9508 * *$ \\
\hline$\hat{\mathrm{Y}}_{\mathrm{Mg}}=1,624374+0,002055 *(\mathrm{MS})$ & $0,8179 *$ & $0,7723 *$ \\
\hline$\hat{\mathrm{Y}}_{\mathrm{Zn}}=60,854139+0,013864 * *(\mathrm{MS})$ & $0,9560 * *$ & $0,9450 * *$ \\
\hline$\hat{\mathrm{Y}}_{\mathrm{Mn}}=80,424974+0,274728 * *(\mathrm{MS})$ & $0,9862 * *$ & $0,9827 * *$ \\
\hline$\hat{\mathrm{Y}}_{\mathrm{Cu}}=15,314688+0,007105 * *(\mathrm{MS})$ & $0,9480 * *$ & $0,9307 * *$ \\
\hline \multicolumn{3}{|l|}{ 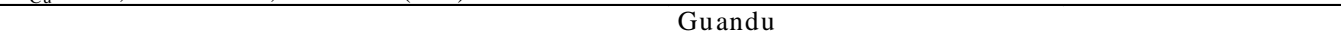 } \\
\hline$\hat{\mathrm{Y}}_{\mathrm{N}}=34,774366+0,023057 * *(\mathrm{MS})$ & $0,8701 * *$ & $0,8376 * *$ \\
\hline$\hat{\mathrm{Y}}_{\mathrm{P}}=1,278159+0,002647 * *(\mathrm{MS})$ & $0,9926 * *$ & $0,9907 * *$ \\
\hline$\hat{\mathrm{Y}}_{\mathrm{K}}=-1,429131+0,014393 * *(\mathrm{MS})$ & $0,9954 * *$ & $0,9942 * *$ \\
\hline$\hat{\mathrm{Y}}_{\mathrm{Ca}}=-4,301165+0,008797 * *(\mathrm{MS})$ & $0,9137 * *$ & $0,8921 * *$ \\
\hline$\hat{\mathrm{Y}}_{\mathrm{Mg}}=1,742984+0,002288 * *(\mathrm{MS})$ & $0,9907 * *$ & $0,9883 * *$ \\
\hline$\hat{\mathrm{Y}}_{\mathrm{Zn}}=28,645659+0,019781 * *(\mathrm{MS})$ & $0,9755^{* *}$ & $0,9694 * *$ \\
\hline$\hat{\mathrm{Y}}_{\mathrm{Mn}}=142,756965+0,064628 *(\mathrm{MS})$ & $0,8306 *$ & $0,7741 *$ \\
\hline$\hat{\mathrm{Y}}_{\mathrm{Cu}}=-132,072160+0,055724 * *(\mathrm{MS})$ & $0,9100 * *$ & $0,8876 * *$ \\
\hline \multicolumn{3}{|c|}{ Mucuna-preta } \\
\hline$\hat{\mathrm{Y}}_{\mathrm{N}}=22,029026+0,028317 *(\mathrm{MS})$ & $0,9265^{*}$ & $0,8898 *$ \\
\hline$\hat{\mathrm{Y}}_{\mathrm{P}}=3,041221+0,002656 *(\mathrm{MS})$ & $0,9543 *$ & $0,9315 *$ \\
\hline$\hat{\mathrm{Y}}_{\mathrm{K}}=-1,550650+0,017515 * *(\mathrm{MS})$ & $0,9814 * *$ & $0,9721 * *$ \\
\hline$\hat{\mathrm{Y}}_{\mathrm{Ca}}=21,224584+0,006901^{\mathrm{ns}}(\mathrm{MS})$ & $0,6284^{\mathrm{ns}}$ & $0,4425^{\mathrm{ns}}$ \\
\hline$\hat{\mathrm{Y}}_{\mathrm{Mg}}=1,315506+0,002718 *(\mathrm{MS})$ & $0,9459 *$ & $0,9189 *$ \\
\hline$\hat{\mathrm{Y}}_{\mathrm{Zn}}=17,662324+0,024570 *(\mathrm{MS})$ & $0,9679 * *$ & $0,9518 * *$ \\
\hline$\hat{\mathrm{Y}}_{\mathrm{Mn}}=208,755589+0,085684^{\mathrm{ns}}(\mathrm{MS})$ & $0,7921^{\mathrm{ns}}$ & $0,6881^{\mathrm{ns}}$ \\
\hline$\hat{\mathrm{Y}}_{\mathrm{Cu}}=20,257345+0,013500 *(\mathrm{MS})$ & $0,9757 * *$ & $0,9636 * *$ \\
\hline \multicolumn{3}{|c|}{ Tremoço } \\
\hline$\hat{\mathrm{Y}}_{\mathrm{N}}=-18,883901+0,035905 * *(\mathrm{MS})$ & $0,9979 * *$ & $0,9969 * *$ \\
\hline$\hat{\mathrm{Y}}_{\mathrm{P}}=3,464729+0,001358 *(\mathrm{MS})$ & $0,9786 * *$ & $0,9679 * *$ \\
\hline$\hat{\mathrm{Y}}_{\mathrm{K}}=55,403253+0,013052 *(\mathrm{MS})$ & $0,9675^{*}$ & $0,9513 *$ \\
\hline$\hat{\mathrm{Y}}_{\mathrm{Ca}}=3,691804+0,011431 *(\mathrm{MS})$ & $0,9671 *$ & $0,9506 *$ \\
\hline$\hat{\mathrm{Y}}_{\mathrm{Mg}}=-0,159443+0,002717 *(\mathrm{MS})$ & $0,9710 *$ & $0,9565 *$ \\
\hline$\hat{\mathrm{Y}}_{\mathrm{Zn}}=114,607845+0,028733 * *(\mathrm{MS})$ & $0,9837 * *$ & $0,9756 * *$ \\
\hline$\hat{\mathrm{Y}}_{\mathrm{Cu}}=122,161248+0,007494^{\mathrm{ns}}(\mathrm{MS})$ & $0,8063^{\mathrm{ns}}$ & $0,7095^{\mathrm{ns}}$ \\
\hline
\end{tabular}

ns Não-significativo. * e **Significativo a $5 \%$ e a $1 \%$ de probabilidade, respectivamente. 
intervalos de classe de rendimento de MS, variando de $<2,5 \mathrm{tha}^{-1}$ até $>7,5 \mathrm{tha}^{-1}$. A distribuição de freqüência ficou concentrada entre dois intervalos de classes, >2,5 a 5,0 e >5,0 a 7,5 tha-1, com nove observações em cada classe (Tabela 1). Essas produções de MS estão de acordo com as apresentadas por Bulisani et al. (1992) e por Calegari (1995), de $4 \mathrm{a} \mathrm{7,5} \mathrm{t} \mathrm{ha}^{-1} \mathrm{ano}^{-1}$. As menores produções de MS foram verificadas quando a mucuna foi consorciada com milho.

A mucuna, assim como as leguminosas em geral, apresenta elevados teores de $\mathrm{N}$ na biomassa, podendo acumular de 66 a $280 \mathrm{~kg} \mathrm{ha}^{-1}$ de N, com rendimento de MS entre 1,7 e 8,6 $\mathrm{t} \mathrm{ha}^{-1}$ (Tabela 5). Essa espécie também recicla quantidades consideráveis de $\mathrm{P}$ e $\mathrm{K}$ e acumula maiores quantidades de $\mathrm{P}$ por tonelada de MS quando comparada à aveia-preta, mas o inverso ocorre em relação ao K (Tabela 6).

Em relação às quantidades de $\mathrm{Ca}$ e de $\mathrm{Mg}$, as cinco espécies apresentam valores muito semelhantes por tonelada de MS. Exceto na aveia-preta, na qual a quantidade média de Ca por tonelada de MS foi menor do que a observada nas outras espécies (Tabela 6). Quanto aos micronutrientes, a mucuna acumulou quantidades intermediárias de Zn, Mn e $\mathrm{Cu}$, por tonelada de $\mathrm{MS}$, comparada com as demais espécies avaliadas (Tabela 6).

Tabela 4. Quantidades de nutrientes minerais contidos na matéria seca de guandu passíveis de retornar ao solo pela mineralização da biomassa.

\begin{tabular}{|c|c|c|c|c|c|c|}
\hline \multirow[t]{2}{*}{ Variável } & \multicolumn{6}{|c|}{ Intervalo de classe de rendimento de MS $\left(\mathrm{t} \mathrm{ha}^{-1}\right)$} \\
\hline & $<2$ & $>2$ a 4 & $>4$ a 6 & $>6$ a 8 & $>8$ a 10 & $>10$ \\
\hline & \multicolumn{6}{|c|}{ Nitrogênio $\left(\mathrm{kg} \mathrm{ha}^{-1}\right)$} \\
\hline Média observada & 43 & 87 & 151 & 226 & 288 & 267 \\
\hline Média estimada & 67 & 101 & 144 & 191 & 243 & 316 \\
\hline \multirow[t]{2}{*}{ IC a $95 \%$} & 0 a 141 & 40 a 162 & 95 a 192 & 145 a 237 & 186 a 301 & 229 a 403 \\
\hline & \multicolumn{6}{|c|}{ Fósforo $\left(\mathrm{kg} \mathrm{ha}^{-1}\right)$} \\
\hline Média observada & 4 & 8 & 15 & 20 & 25 & 33 \\
\hline Média estimada & 5 & 9 & 14 & 19 & 25 & 33 \\
\hline \multirow[t]{2}{*}{ IC a $95 \%$} & 3 a 7 & 7 a 10 & 12 a 15 & 18 a 20 & 24 a 27 & 31 a 36 \\
\hline & \multicolumn{6}{|c|}{ Potássio $\left(\mathrm{kg} \mathrm{ha}^{-1}\right)$} \\
\hline Média observada & 20 & 41 & 67 & 89 & 134 & 174 \\
\hline Média estimada & 19 & 40 & 67 & 96 & 129 & 174 \\
\hline \multirow[t]{2}{*}{ IC a $95 \%$} & 10 a 27 & 33 a 46 & 61 a 72 & 91 a 101 & 122 a 135 & 164 a 184 \\
\hline & \multicolumn{6}{|c|}{ Cálcio $\left(\mathrm{kg} \mathrm{ha}^{-1}\right)$} \\
\hline Média observada & 13 & 28 & 36 & 41 & 64 & 117 \\
\hline Média estimada & 8 & 21 & 37 & 55 & 75 & 103 \\
\hline \multirow[t]{2}{*}{ IC a $95 \%$} & 0 a 30 & 2 a 40 & 22 a 52 & 42 a 69 & 58 a 93 & 76 a 129 \\
\hline & \multicolumn{6}{|c|}{ Magnésio $\left(\mathrm{kg} \mathrm{ha}^{-1}\right)$} \\
\hline Média observada & 4 & 8 & 13 & 18 & 23 & 28 \\
\hline Média estimada & 5 & 8 & 13 & 17 & 22 & 30 \\
\hline \multirow[t]{2}{*}{ IC a $95 \%$} & 3 a 7 & 7 a 10 & 11 a 14 & 16 a 18 & 21 a 24 & 27 a 32 \\
\hline & \multicolumn{6}{|c|}{ Zinco $\left(\mathrm{g} \mathrm{ha}^{-1}\right)$} \\
\hline Média observada & 37 & 103 & 130 & 158 & 208 & 267 \\
\hline Média estimada & 56 & 85 & 122 & 162 & 208 & 270 \\
\hline \multirow[t]{2}{*}{ IC a $95 \%$} & 30 a 82 & 64 a 107 & 105 a 139 & 146 a 179 & 187 a 228 & 239 a 300 \\
\hline & \multicolumn{6}{|c|}{ Manganês $\left(\mathrm{g} \mathrm{ha}^{-1}\right)$} \\
\hline Média observada & 124 & 404 & 494 & 650 & 644 & 788 \\
\hline Média estimada & 233 & 328 & 448 & 580 & 728 & 931 \\
\hline \multirow[t]{2}{*}{ IC a $95 \%$} & 0 a 474 & 143 a 512 & 301 a 595 & 405 a 756 & 464 a 991 & 516 a 1.345 \\
\hline & \multicolumn{6}{|c|}{ Cobre $\left(\mathrm{g} \mathrm{ha}^{-1}\right)$} \\
\hline Média observada & 19 & 51 & 73 & 147 & 356 & 622 \\
\hline Média estimada & 0 & 28 & 131 & 245 & 372 & 547 \\
\hline IC a $95 \%$ & 0 a 92 & 0 a 148 & 35 a 227 & 155 a 336 & 259 a 486 & 376 a 719 \\
\hline
\end{tabular}


As equações ajustadas para estimar as quantidades de nutrientes apresentaram coeficientes de determinação $\left(\mathrm{R}^{2}\right)$ superiores a 0,92 e significativos a $5 \%$ de probabilidade, com exceção das equações ajustadas para o Ca e para o Mn (Tabela 3).

O rendimento de MS de tremoço foi estimado em 87 amostras coletadas, cuja distribuição dentro dos quatro intervalos de classe foi equilibrada, com um número considerável de observações tanto no limite inferior (<7,0 $\mathrm{t} \mathrm{ha}^{-1}$ de MS) como no grupo com mais de 13,0 t ha ${ }^{-1}$ de MS e nas classes intermediárias (Tabela 1).

A quantidade de $\mathrm{N}$ acumulada por tonelada de MS pelo tremoço é semelhante à encontrada no guandu e na mucuna-preta, aproximadamente 30 a $34 \mathrm{~kg} \mathrm{ha}^{-1}$ de $\mathrm{N}$, porém seu conteúdo de $\mathrm{P}$ na MS é menor do que o verificado nessas duas espécies (Tabela 6).

As quantidades de $\mathrm{Ca}$ e $\mathrm{Mg}$ do tremoço e da mucuna-preta por unidade de MS da biomassa são semelhantes. A mucuna, todavia, como foi, em alguns casos, cultivada em consórcio com o milho, produziu em média a metade de MS em relação ao tremoço e, conseqüentemente, as quantidades acumuladas foram menores. Quanto aos micronutrientes, embora não haja informações em relação ao $\mathrm{Mn}$, o tremoço acumula muito mais $\mathrm{Zn}$ e $\mathrm{Cu}$ do que as outras espécies estudadas e que apresentaram rendimento de MS superior a $10 \mathrm{t} \mathrm{ha}^{-1}$ (Tabela 7).

Tabela 5. Quantidades de nutrientes minerais contidos na matéria seca de mucuna-preta passíveis de retornar ao solo pela mineralização da biomassa.

\begin{tabular}{|c|c|c|c|c|}
\hline \multirow[t]{2}{*}{ Variável } & \multicolumn{4}{|c|}{ Intervalo de classe de rendimento de $\mathrm{MS}\left(\mathrm{t} \mathrm{ha}^{-1}\right)$} \\
\hline & $<2,5$ & $>2,5$ a 5,0 & $>5,0$ a 7,5 & $>7,5$ \\
\hline & \multicolumn{4}{|c|}{ Nitrogênio $\left(\mathrm{kg} \mathrm{ha}^{-1}\right)$} \\
\hline Média observada & 66 & 156 & 164 & 280 \\
\hline Média estimada & 70 & 134 & 195 & 267 \\
\hline \multirow[t]{2}{*}{ IC a $95 \%$} & 0 a 174 & 65 a 202 & 128 a 262 & 160 a 373 \\
\hline & \multicolumn{4}{|c|}{ Fósforo $\left(\mathrm{kg} \mathrm{ha}^{-1}\right)$} \\
\hline Média observada & 6 & 16 & 18 & 26 \\
\hline Média estimada & 8 & 14 & 19 & 26 \\
\hline \multirow[t]{2}{*}{ IC a $95 \%$} & 0 a 15 & 8 a 18 & 14 a 24 & 18 a 34 \\
\hline & \multicolumn{4}{|c|}{ Potássio $\left(\mathrm{kg} \mathrm{ha}^{-1}\right)$} \\
\hline Média observada & 25 & 67 & 116 & 144 \\
\hline Média estimada & 28 & 67 & 105 & 150 \\
\hline \multirow[t]{2}{*}{ IC a $95 \%$} & 0 a 59 & 47 a 88 & 85 a 126 & 118 a 182 \\
\hline & \multicolumn{4}{|c|}{ Cálcio $\left(\mathrm{kg} \mathrm{ha}^{-1}\right)$} \\
\hline Média observada & 18 & 66 & 72 & 70 \\
\hline Média estimada & 33 & 48 & 63 & 81 \\
\hline \multirow[t]{2}{*}{ IC a $95 \%$} & 0 a 102 & 3 a 94 & 19 a 108 & 10 a 160 \\
\hline & \multicolumn{4}{|c|}{ Magnésio $\left(\mathrm{kg} \mathrm{ha}^{-1}\right)$} \\
\hline Média observada & 4 & 15 & 17 & 24 \\
\hline Média estimada & 6 & 12 & 18 & 25 \\
\hline \multirow[t]{2}{*}{ IC a $95 \%$} & 0 a 14 & 6 a 18 & 12 a 23 & 16 a 33 \\
\hline & \multicolumn{4}{|c|}{ Zinco $\left(\mathrm{g} \mathrm{ha}^{-1}\right)$} \\
\hline Média observada & 54 & 130 & 153 & 235 \\
\hline Média estimada & 59 & 114 & 168 & 230 \\
\hline \multirow[t]{2}{*}{ IC a $95 \%$} & 1 a 117 & 76 a 153 & 130 a 205 & 170 a 290 \\
\hline & \multicolumn{4}{|c|}{ Manganês $\left(\mathrm{g} \mathrm{ha}^{-1}\right)$} \\
\hline Média observada & 353 & 647 & 549 & 1.033 \\
\hline Média estimada & 354 & 546 & 732 & 949 \\
\hline \multirow[t]{2}{*}{ IC a $95 \%$} & 0 a 920 & 169 a 923 & 363 a 1.101 & 364 a 1.534 \\
\hline & \multicolumn{4}{|c|}{ Cobre $\left(\mathrm{g} \mathrm{ha}^{-1}\right)$} \\
\hline Média observada & 38 & 83 & 100 & 136 \\
\hline Média estimada & 43 & 73 & 103 & 137 \\
\hline IC a $95 \%$ & 16 a 71 & 55 a 92 & 85 a 121 & 109 a 165 \\
\hline
\end{tabular}


As equações ajustadas para estimar as quantidades de nutrientes do tremoço apresentaram $\mathrm{R}^{2}$ maiores que 0,96 e significativos a $5 \%$ de probabilidade, com exceção da equação para estimar o conteúdo de $\mathrm{Cu}$ (Tabela 3).
A ervilhaca, leguminosa pouco utilizada nos sistemas de rotação de culturas, teve somente 12 amostras coletadas. Por apresentar valores de peso de MS semelhantes, não foi possível separá-los em classes e analisá-los estatisticamente (Tabela 8). O rendi-

Tabela 6. Quantidades médias de matéria seca e de nutrientes na matéria seca das cinco espécies de plantas de cobertura do solo utilizadas em rotação de culturas.

\begin{tabular}{lrrrrr}
\hline Nutrientes analisados & Aveia-preta & Guandu & Mucuna-preta & Tremoço & Ervilhaca \\
\hline $\mathrm{N}\left(\mathrm{kg} \mathrm{t}^{-1}\right)$ & 13,7 & 30,1 & 34,4 & 33,8 & 46,2 \\
$\mathrm{P}\left(\mathrm{kg} \mathrm{t}^{-1}\right)$ & 1,3 & 2,9 & 3,4 & 1,7 & 3,4 \\
$\mathrm{~K}\left(\mathrm{~kg} \mathrm{t}^{-1}\right)$ & 23,3 & 14,2 & 16,8 & 19,2 & 22,9 \\
$\mathrm{Ca}\left(\mathrm{kg} \mathrm{t}^{-1}\right)$ & 7,8 & 8,2 & 11,8 & 11,9 & 10,5 \\
$\mathrm{Mg}\left(\mathrm{kg} \mathrm{t}^{-1}\right)$ & 2,3 & 2,6 & 2,9 & 2,7 & 2,6 \\
$\mathrm{Zn}\left(\mathrm{g} \mathrm{t}^{-1}\right)$ & 21,0 & 26,4 & 29,2 & 41,5 & 31,9 \\
$\mathrm{Mn}\left(\mathrm{g} \mathrm{t}^{-1}\right)$ & 286,0 & 94,4 & 145,4 & - & 69,3 \\
$\mathrm{Cu}\left(\mathrm{g} \mathrm{t}^{-1}\right)$ & 9,0 & 26,5 & 18,9 & 21,2 & 10,3 \\
\hline Matéria seca $\left(\mathrm{kg} \mathrm{ha}^{-1}\right)$ & 10.334 & 6.165 & 5.097 & 10.094 & 5.328 \\
\hline
\end{tabular}

Tabela 7. Quantidades de nutrientes minerais contidos na matéria seca de tremoço passíveis de retornar ao solo pela mineralização da biomassa.

\begin{tabular}{|c|c|c|c|c|}
\hline \multirow[t]{2}{*}{ Variável } & \multicolumn{4}{|c|}{ Intervalo de classe de rendimento de $\mathrm{MS}\left(\mathrm{t} \mathrm{ha}^{-1}\right)$} \\
\hline & $<7,0$ & $>7$ a 10,0 & $>10,0$ a 13,0 & $>13,0$ \\
\hline & \multicolumn{4}{|c|}{ Nitrogênio $\left(\mathrm{kg} \mathrm{ha}^{-1}\right)$} \\
\hline Média observada & 186 & 291 & 406 & 492 \\
\hline Média estimada & 188 & 291 & 398 & 497 \\
\hline \multirow[t]{2}{*}{$\mathrm{IC}$ a $95 \%$} & 162 a 215 & 273 a 308 & 380 a 415 & 471 a 524 \\
\hline & \multicolumn{4}{|c|}{ Fósforo $\left(\mathrm{kg} \mathrm{ha}^{-1}\right)$} \\
\hline Média observada & 11 & 16 & 19 & 23 \\
\hline Média estimada & 11 & 15 & 19 & 23 \\
\hline \multirow[t]{2}{*}{ IC a $95 \%$} & 8 a 15 & 13 a 17 & 17 a 21 & 20 a 26 \\
\hline & \multicolumn{4}{|c|}{ Potássio $\left(\mathrm{kg} \mathrm{ha}^{-1}\right)$} \\
\hline Média observada & 130 & 174 & 194 & 249 \\
\hline Média estimada & 131 & 168 & 207 & 243 \\
\hline \multirow[t]{2}{*}{ IC a $95 \%$} & 92 a 170 & 142 a 194 & 181 a 233 & 204 a 282 \\
\hline & \multicolumn{4}{|c|}{ Cálcio $\left(\mathrm{kg} \mathrm{ha}^{-1}\right)$} \\
\hline Média observada & 75 & 91 & 142 & 168 \\
\hline Média estimada & 70 & 102 & 136 & 168 \\
\hline \multirow[t]{2}{*}{ IC a $95 \%$} & 35 a 104 & 80 a 125 & 114 a 159 & 134 a 202 \\
\hline & \multicolumn{4}{|c|}{ Magnésio $\left(\mathrm{kg} \mathrm{ha}^{-1}\right)$} \\
\hline Média observada & 16 & 21 & 33 & 38 \\
\hline Média estimada & 16 & 23 & 31 & 39 \\
\hline \multirow[t]{2}{*}{ IC a $95 \%$} & 8 a 23 & 18 a 28 & 26 a 36 & $31 \mathrm{a} 47$ \\
\hline & \multicolumn{4}{|c|}{ Zinco $\left(\mathrm{g} \mathrm{ha}^{-1}\right)$} \\
\hline Média observada & 283 & 350 & 466 & 520 \\
\hline Média estimada & 280 & 362 & 448 & 528 \\
\hline \multirow{2}{*}{ IC a $95 \%$} & 220 a 341 & 323 a 402 & 408 a 488 & 467 a 588 \\
\hline & \multicolumn{4}{|c|}{ Cobre $\left(\mathrm{g} \mathrm{ha}^{-1}\right)$} \\
\hline Média observada & 175 & 179 & 194 & 243 \\
\hline Média estimada & 165 & 187 & 209 & 230 \\
\hline IC a $95 \%$ & 105 a 226 & 147 a 226 & 169 a 249 & 170 a 290 \\
\hline
\end{tabular}


mento máximo de MS foi de 6,5 tha $\mathrm{th}^{-1}$ e embora os valores observados de MS não foram elevados, essa espécie apresentou grandes quantidades de N, P, K, $\mathrm{Ca}$ e $\mathrm{Mg}$ acumuladas por unidade de MS (Tabela 6).

Em relação aos micronutrientes, a quantidade de Mn acumulada não foi muito expressiva $\left(69,3 \mathrm{~g} \mathrm{t}^{-1}\right.$ de MS) se comparada com as demais espécies. Por sua vez, as quantidades de $\mathrm{Zn}$ e $\mathrm{Cu}$ foram intermediárias (Tabela 6). As equações ajustadas para estimar as quantidades de N, K, Mg e Zn acumuladas apresentaram coeficientes de determinação $\left(\mathrm{R}^{2}\right)$ elevados e significativos, mas os modelos ajustados para $\mathrm{P}, \mathrm{Ca}, \mathrm{Mn}$ e $\mathrm{Cu}$ apresentaram valores de $\mathrm{R}^{2}$ baixos (Tabela 9).

Diante das diferenças na quantidade de elementos químicos adicionados ao solo por intermédio das diversas espécies de cobertura do solo, é possível inferir que essas espécies podem ser utilizadas para

Tabela 8. Quantidades de nutrientes acumulados na matéria seca de ervilhaca, passíveis de retornar ao solo pela mineralização da biomassa $(\mathrm{n}=12)$.

\begin{tabular}{lrrr}
\hline Nutrientes analisados & Médias & $\begin{array}{c}\text { Menor } \\
\text { valor }\end{array}$ & $\begin{array}{r}\text { Maior } \\
\text { valor }\end{array}$ \\
\hline $\mathrm{N}\left(\mathrm{kg} \mathrm{ha}^{-1}\right)$ & 246 & 148 & 316 \\
$\mathrm{P}\left(\mathrm{kg} \mathrm{ha}^{-1}\right)$ & 18 & 13 & 25 \\
$\mathrm{~K}\left(\mathrm{~kg} \mathrm{ha}^{-1}\right)$ & 122 & 73 & 175 \\
$\mathrm{Ca}\left(\mathrm{kg} \mathrm{ha}^{-1}\right)$ & 56 & 48 & 74 \\
$\mathrm{Mg}\left(\mathrm{kg} \mathrm{ha}^{-1}\right)$ & 14 & 8 & 20 \\
$\mathrm{Zn}\left(\mathrm{g} \mathrm{ha}^{-1}\right)$ & 170 & 109 & 239 \\
$\mathrm{Mn}\left(\mathrm{g} \mathrm{ha}^{-1}\right)$ & 369 & 231 & 490 \\
$\mathrm{Cu}\left(\mathrm{g} \mathrm{ha}^{-1}\right)$ & 55 & 34 & 71 \\
\hline Mat. seca $\left(\mathrm{kg} \mathrm{ha}^{-1}\right)$ & 5.328 & 4.202 & 6.507 \\
\hline
\end{tabular}

Tabela 9. Equações ajustadas para estimar $(\hat{\mathrm{Y}})$ as quantidades de N, P, K, Ca e Mg, em kg ha-1, e de Zn, Mn e Cu, em $\mathrm{g} \mathrm{ha}^{-1}$, acumuladas na matéria seca (MS) e passíveis de ser recicladas pela ervilhaca.

\begin{tabular}{lll}
\hline Equação & \multicolumn{1}{c}{$\mathrm{R}^{2}$} & \multicolumn{1}{c}{$\mathrm{R}_{\text {ajustado }}$} \\
\hline$\hat{\mathrm{Y}}_{\mathrm{N}}=-683,862037+0,286332 *(\mathrm{MS})$ & $0,9354^{* *}$ & $0,9210^{* *}$ \\
$-0,0000205^{\circ}(\mathrm{MS})^{2}$ & & \\
$\hat{\mathrm{Y}}_{\mathrm{P}}=7,237648+0,002087^{\circ}(\mathrm{MS})$ & $0,2494^{\mathrm{ns}}$ & $0,1743^{\text {ns }}$ \\
$\hat{\mathrm{Y}}_{\mathrm{K}}=-79,908671+0,037813^{* *}(\mathrm{MS})$ & $0,8567^{* *}$ & $0,8423^{* *}$ \\
$\hat{\mathrm{Y}}_{\mathrm{Ca}}=17,051893+0,007339^{*}(\mathrm{MS})$ & $0,4282^{*}$ & $0,3646^{*}$ \\
$\hat{\mathrm{Y}}_{\mathrm{Mg}}=-12,306823+0,004954^{* *}(\mathrm{MS})$ & $0,9547^{* *}$ & $0,9501^{* *}$ \\
$\hat{\mathrm{Y}}_{\mathrm{Zn}}=-93,673014+0,049420^{* *}(\mathrm{MS})$ & $0,8849^{* *}$ & $0,8734^{* *}$ \\
$\hat{\mathrm{Y}}_{\mathrm{Mn}}=-69,247540+0,081275^{*}(\mathrm{MS})$ & $0,4905^{*}$ & $0,4396^{*}$ \\
$\hat{\mathrm{Y}}_{\mathrm{Cu}}=92,293587-0,006968^{\mathrm{n}}(\mathrm{MS})$ & $0,2453^{\text {ns }}$ & $0,1699^{\text {ns }}$ \\
\hline
\end{tabular}

nsNão-significativo. ${ }^{\circ}, *$ e **Significativo a $10 \%$, a $5 \%$ e a $1 \%$ de probabilidade, respectivamente. evitar o esgotamento do solo, repondo os nutrientes essenciais extraídos pelas culturas comerciais no processo produtivo. A rotação de culturas, ao introduzir a biodiversidade, é uma prática que viabiliza a semeadura direta com equilíbrio das relações de manutenção da produtividade do solo. Em rotação de culturas, quanto maior for a diversificação de espécies maior será a quantidade de nutrientes reciclados por essas espécies e disponibilizados para a atividade produtiva econômica. Por causa da suscetibilidade às doenças comuns entre as espécies de cobertura e as culturas comercialmente exploradas, não é indicada a utilização de uma mesma espécie para cobertura vegetal por dois ou mais anos seguidos em uma mesma área, e o intervalo mínimo permitido não deve ser inferior a três anos. Por isso, os sistemas de rotação recomendados devem ter, no mínimo, quatro anos.

Os resultados obtidos no presente trabalho revelam que as espécies vegetais usadas na cobertura do solo são fundamentais para viabilizar e aumentar a eficiência da semeadura direta. Consórcios de milho/guandu ou milho/mucuna são exemplos de tecnologia de duplo propósito, em que se produz grãos e cobertura vegetal do solo ao mesmo tempo, contribuindo para a melhoria dos atributos do solo e no aumento de rendimento, com reflexos econômicos positivos para o produtor rural.

\section{Conclusões}

1. As espécies avaliadas são eficientes em acumular macronutrientes e micronutrientes, com exceção do fósforo.

2. A aveia-preta e a ervilhaca acumulam grande quantidade de potássio; já a mucuna-preta, o guandu, a ervilhaca e o tremoço acumulam quantidades apreciáveis de nitrogênio; todas as espécies acumulam $\mathrm{Ca}$, $\mathrm{Mg}$ e micronutrientes em quantidades satisfatórias.

3. A rotação de culturas comerciais com espécies para cobertura vegetal do solo sob semeadura direta é fundamental para a implantação e a continuidade de sistemas produtivos sustentáveis, mediante eficiente reciclagem de nutrientes.

\section{Agradecimentos}

Ao CNPq, pelas bolsas de produtividade de pesquisa e de iniciação científica. 


\section{Referências}

ANGHINONI, I.; SALET, R. L. Amostragem de solo e as recomendações de adubação e calagem no sistema de plantio direto. In: NUERNBERG, N. J. (Ed.). Plantio direto: conceitos, fundamentos e práticas culturais. Lages: Sociedade Brasileira de Ciência do Solo, 1996. p. 27-52.

BREMNER, J. M. Total nitrogen. In: BLACK, C. A. (Ed.) Methods of soil analysis. Madison: American Society of Agronomy, 1965. p. 1149-1178.

BROMFIELD, S. M. Sheep faces in relation to the phosphorus cycle under pastures. Australian Journal of Agricultural Research, Melbourne, v. 12, n. 1, p. 111-123, 1961 .

BROMFIELD, S. M.; JONES, O. L. The effect of sheep on the recycling of phosphorus in hayed-off pastures. Australian Journal of Agricultural Research, Melbourne, v. 21, n. 4, p. 699-711, 1970.

BULISANI, E. A.; COSTA, M. B. B. da; MIYAZAKA, S.; CALEGARI, A.; WILDNER, L. do P.; AMARO, T. J. C.; MONDARDO, A. Adubação verde nos Estados de São Paulo, Paraná, Santa Catarina e Rio Grande do Sul. In: CALEGARI, A.; MONDARDO, A.; BULISANI, E. A.; WILDNER, L. do P.; COSTA, M. B. B. da; ALCANTARA, P. B.; MIYASAKA, S.; AMADO, T. J. C. (Ed.). Adubação verde no sul do Brasil. Rio de Janeiro: Assessoria e Serviços a Projetos em Agricultura Alternativa, 1992. pt. 2, p. 57-206.

CALEGARI, A. Leguminosas para adubação verde no Paraná. Londrina: Instituto Agronômico do Paraná, 1995. 118 p. (Circular, 80).

CALEGARI, A. Plantas para adubação verde de inverno no sudoeste do Paraná. Londrina: Instituto Agronômico do Paraná, 1990. 37 p. (Boletim Técnico, 35).

DE-POLLI, H.; CHADA, S. de S. Adubação verde incorporada ou em cobertura na produção de milho em solo de baixo potencial de produtividade. Revista Brasileira de Ciência do Solo, Campinas, v. 13, n. 3, p. 287-293, 1989.

DERPSCH, R.; CALEGARI, A. Plantas para adubação verde de inverno. Londrina: Instituto Agronômico do Paraná, 1992. 80 p. (Circular, 73).

DERPSCH, R.; ROTH, C. H.; SIDIRAS, N.; KÖPKE, U. Controle da erosão no Paraná, Brasil: sistemas de cobertura do solo, plantio direto e preparo conservacionista do solo. Eschborn: Deutsche Gesellschaft für Technische Zusammenarbeit, 1991. 272 p. (Sonderpublikation der GTZ, 245).
IGUE, K.; ALCOVER, M.; DERPSCH, R.; PAVAN, M. A.; MELLA, S. C.; MEDEIROS, G. B. Adubação orgânica. Londrina: Instituto Agronômico do Paraná, 1984. (Informe da Pesquisa, 59).

JONES, M. B.; WOODMANSEE, R. G. Biogeochemical cycling in annual grassland ecosystems. Botany Review, New York, v. 45, n. 2, p. 111-144, 1979.

MIYAZAWA, M.; PAVAN, M. A.; BLOCH, M. de F. Análise química de tecido vegetal. Londrina: Instituto Agronômico do Paraná, 1992. 17 p. (Circular, 74).

MONEGAT, C. Plantas de cobertura do solo: características e manejo em pequenas propriedades. Chapecó, Ed. do Autor, 1981. 336 p.

NEWBOULD, P. Principles of nutrient cycling: elements, compartments, pathways and transfers, time scales, rates of transfer and nutrient balances. In: FRISSEL, M. J. (Ed.). Cycling of mineral nutrients in agricultural ecosystems. Amsterdam: Elsevier, 1978. cap. 2, p. 3-6.

PARANÁ. Secretaria da Agricultura e do Abastecimento. Departamento de Economia Rural. Previsão e estimativas de safras: grãos, algodão, hortaliças e outras culturas: comparativo de área e produção no Paraná, nas safras 00/01 - 01/02. Disponível em: <http://www.pr.gov.br/ seab>. Acesso em: 9 ago. 2002.

SÁ, J. C. M. Manejo da fertilidade do solo no plantio direto. Castro: Fundação ABC, 1993. 96 p.

SPAIN, J. M.; SALINAS, J. G. A reciclagem de nutrientes nas pastagens tropicais. In: REUNIÃO BRASILEIRA DE FERTILIDADE DO SOLO, 16., 1984, Ilhéus. Anais... Ilhéus: Comissão Executiva do Plano da Lavoura Cacaueira, 1985. p. 259-299.

VITTI, G. C.; FERREIRA, A. C.; BRAGA, G.; GOMES, M. T. B. Métodos de análise de elementos em material vegetal. Piracicaba: Esalq, 2000. 28 p.

WHITNEY, A. S.; KANEHIRO, Y. Pathways of nitrogen transfer in some tropical legume grass associations. Agronomy Journal, Madison, v. 59, n. 6, p. 585-588, 1967.

WILKINSON, S. R.; LOWREY, R. W. Cycling of mineral nutrients in pasture ecosystems. In: BUTLER, G. W.; BAILEY, R. W. (Ed.). Chemistry and biochemistry of herbage. London: Academic, 1973. p. 247-325.

WISNIEWSKI, C.; HOLTZ, G. P. Decomposição da palhada e liberação de nitrogênio e fósforo numa rotação aveia-soja sob plantio direto. Pesquisa Agropecuária Brasileira, Brasília, v. 32, n. 11, p. 1191-1197, nov. 1997. 